\title{
Spatial distribution and determinant factors of Female Genital Mutilation among reproductive age women in Ethiopia, 2016; Based on Ethiopian National Demographic and Health Survey
}

Atalay Goshu Muluneh ( $\square$ atalayg1921@gmail.com )

University of Gondar https://orcid.org/0000-0002-2556-4158

Getahun Molla Kassa

University of Gondar

Mehari WoldeMariam Merid

University of Gondar

Research article

Keywords: Female Genital Mutilations, Spatial analysis, Multi-level analysis

Posted Date: June 24th, 2020

DOI: https://doi.org/10.21203/rs.2.13810/v4

License: (a) (1) This work is licensed under a Creative Commons Attribution 4.0 International License. Read Full License 


\section{Abstract}

Background: Though condemned and considered as a crime by the countries government, Female Genital Mutilation (FGM) remains a common public health problem in Africa and Ethiopia as well. Every year, more than 3 million females undergo FGM and most of them are in Africa. Thus, this study was aimed to assess the spatial distribution and associated factors of female genital mutilation in Ethiopia based on the Ethiopian demographic and Health Survey 2016 data.

Method: This is a secondary data analysis of Ethiopian Demographic and Health Survey (EDHS) 2016 data based on 7,163 women who were included for the FGM interview. The data were weighted using sampling weight as recommended by the program. The MS Excel and ArcGIS 10.3 software were used for data cleaning and spatial analysis respectively. Global and local level clustering was assessed. For the none spatial data and the determinant factors, data cleaning and analysis were done using STATA 14. Since the data has significant clustering with the Intraclass Correlation Coefficient [ICC $=0.61(0.56,0.65)]$, a multi-level mixed-effect logistic regression model was fitted. Variables with a P-value $<0.25$ in the bi-variable analysis were fitted in the multi-variable analysis. Finally, variables with $p$-value $<0.05$ with $95 \% \mathrm{Cl}$ of adjusted odds ratio were reported as a statistically significant determinant of FGM.

Result: Female genital mutilation was spatially clustered (Global Moran's I: $0.48, p<0.001)$. Significant hot spot clusters were found in Eastern-Amhara, Oromia, Southern Nations Nationalities and Peoples (SNNP) regions, Dire-Dawa, and Harari. Mothers age $>30$ $(A O R=2.41,95 \% \mathrm{Cl}: 1.78,3.26)$ years, never in union ( $A O R=0.31,95 \% \mathrm{Cl}: 0.22,0.44)$, currently not working (AOR=0.71, 95\%Cl: 0.55, 0.92), women who considered FGM to be continued (AOR=2.86, 95\% Cl: $1.75,4.68)$, not heard of FGM ( $\mathrm{AOR}=0.22,95 \% \mathrm{Cl}: 0.08,0.62)$, had no formal education (AOR=1.67, 95\% Cl: 1.03, 2.71), Muslim (AOR=3.90, 95\% Cl:2.5, 6.09) and protestant (AOR=1.76, 95\% Cl: 1.25, 2.97), and those who thought of $F G M$ required by religion ( $A O R=1.99,95 \% \mathrm{Cl}: 1.31,2.99)$ were found to be significant determinants of female genital mutilation.

Conclusion: Female genital mutilation was spatially clustered with hotspot areas found:in Eastern-Amhara, Oromia, and SNNP regions, Dire-Dawa and Harari administrative. Age of the mother, religion, occupation, educational level, marital status, information about Female genital mutilation, and intention about FGM to be stopped or continued were significant determinants of female genital mutilation

\section{Background}

Female Genital Mutilation [FGM] is a partial or complete removal of external genitalia of the female for none medical reason (1). Four types of FGMs are practiced in different countries ranging from simple clitoridectomy up to infibulations. Type I (clitoridectomy), is a partial or complete removal of the clitoris and/or prepuce; type II (excision), is a total or partial removal of the clitoris and the labia minoria with or without removal of the labia majora; type III (infibulation), involves the narrowing of the vaginal orifice with the creation of a covering seal by cutting and a positioning the labia minora and/or the labia majora, with or without excision of the clitoris; and type IV (all other), all other forms of harmful traditional practice on the female genitalia for a none-medical purpose $(2,3)$. Female genital mutilation is mostly practiced on young girls of infancy up to early adolescence period $(4,5)$.

Globally, more than 200 million women and girls have undergone FGM so far (3). Female genital mutilation is practiced currently in more than 30 countries including Ethiopia (5). Half of the women and girls who undergo FGM lives in three countries including Egypt, Ethiopia and Indonesia (3).According to the Ethiopian Demographic and Health Survey [EDHS] 2016 report, FGM is still a public health problem with a prevalence of $65 \%$ (6). Female genital mutilation is considered as child abuse and gross violation of children's and women's human rights $(4,7,8)$.

Pieces of evidences have noted that female genital mutilation has multitude of health consequences $(1,4,9-14)$. Different studies point out that female genital mutilation had different physical consequences like pain during sexual intercourse, psychological disorder including post-traumatic depression disorders $(15,16)$. For instance, women who were undergone FGM are at high risk of obstetric complications during their childbirth (4). Furthermore, all types of FGM end up with immediate complications like hemorrhage and severe pain that will result in and ultimately death (12). Other short term complications including wound infection, sepsis, tetanus and risk of HIV/AIDS transmissions are also possible causes of death due to FGM $(10-12,14)$. In addition, women who had undergone type II or III FGM increases the risk of needing cesarean section and suffering from postpartum hemorrhage in Africa $(4,10)$.

The World Health Organization (WHO) identified six key factors that determine the continuation of FGM in developing countries. These include cultural traditions, sexual morals, marriageability, religion, health benefits, and male sexual enjoyments $(4,8,14,17-19)$. 
Different stakeholders were involved to decrease female genital mutilation globally $(3,4,20)$. The world has included FGM and other traditional practices as a target to be eliminated by 2030 in support of Sustainable Development Goals (20). Cognizant to this, the government of Ethiopia is struggling to eliminate FGM through prevention, provision, and protection until 2025 (6). Globally, the overall reduction of FGM was observed for the last three decades but the progress is insufficient and uneven over countries for the rapid population growth $(3,4)$.

The united nations have declared female genital mutilation as an illegal act to make the world free from FGM (21). However, it has remained one of the major public health problems which put countries at the high burden of maternal morbidity and mortality in developing countries including Ethiopia (6). As part of this initiative, Ethiopia has developed prevention, protection and provision strategies, criminalization, and refreshed commitments to end FGM by $2025(6,21)$. Despite the above initiatives and efforts attempted by organizations and countries, a significant number of women and girls are practicing FGM mainly in developing countries including Ethiopia. However, there is a dearth of literature regarding the spatial distribution and determinants of FGM. Therefore it is imperative to explore spatial distribution and identify the determinant factors of FGM.

\section{Methods}

\section{Study design and setting}

A secondary data analysis was conducted from Ethiopian Demographic and Health Survey 2016 data. Ethiopia is located in East Africa at $\left(3^{\circ}-14^{\circ} \mathrm{N}\right.$ and $\left.33^{\circ}-48^{\circ} \mathrm{E}\right)$. It has nine regional states (Afar, Amhara, Benishangul-Gumuz, Gambella, Harari, Oromia, Somali, Southern Nations, Nationalities, and People's Region (SNNP), and Tigray) and two administrative cities (Addis Ababa and Dire Dawa). Ethiopia is the $2^{\text {nd }}$ populous country in Africa with a high fertility rate of 4.6 children per woman.

\section{Data source and measurements}

Every five years, the Demographic and Health Survey of Ethiopia (EDHS) collects data at the national level based on representative samples and key indicators including maternal health conditions. The interviewer-administered questionnaire was used to collect data on women of reproductive age (15-49) years. The questionnaire included socio-demographic, socioeconomic, pregnancy, and maternal health service-related variables related to women's health. A stratified two-stage cluster sampling with a total of 645 Enumeration Areas (EAs) (202 in Urban and 443 in rural areas) were selected with probability proportional to EA size. A total of 15,683 women were interviewed for maternal health indicators assessment. Among the 15,683 interviewed, 7,163 households were selected for FGM (6).

Geographic coordinate data (latitude and longitude) were collected for selected enumeration areas. The coordinate data and the data set were accessed through an online request from major DHS International (http://www.dhsprogram.com.) after registration as an authorized user. The shape files of all maps were freely accessible from the link below without restrictions (https://africaopendata.org/dataset/ethiopia-shapefiles).

\section{Data analysis}

As recommended by the major DHS program of Ethiopia, the data was weighted $1^{\text {st }}$ using the code for women data and the detail is found in the major DHS report (6). Data cleaning and descriptive statistics were conducted using STATA 14 software for the nonspatial data. Multicollinearity was checked using Variance Inflation Factor (VIF) by considering a cut-off point of VIF $>10$ to declare as multicollinearity. Geographic Information System (ArcGIS) version10.3 was used for spatial data analysis. We had computed the cluster level observed/expected counts and corresponding standardization ratios. We use this one as an outcome variable for the spatial analysis. Through the whole process of the spatial analysis.. Global and local level spatial autocorrelation analysis techniques were used to test the presence of spatial autocorrelation and for identifying significant clusters. Hot spot analysis was conducted using Getis-Ord Gi* statistics to explore how spatial autocorrelation varies across the study areas. To determine the statistical significance of clustering, the $\mathrm{Gi}^{\star} \mathrm{Z}$ score was computed. A positive $\mathrm{z}$-score $>1.96$ with significant $\mathrm{p}$-value represents hot spot while negative Z-score <-1.96 with significant p-value represents cold spot. Empirical Bayesian kriging prediction was used to predict the unsampled based on the sampled data and creates a smooth surface to predict the burden of FGM across the regions of the country. 
Since the DHS data had hierarchical nature and we got a high and significant clustering $[I C C=0.61(0.56,0.65)]$, we used a multilevel mixed-effect logistic regression model. Variables having a p-value $<0.25$ in the bi-variable multi-level mixed-effect logistic regression model were considered for multivariable analysis(22). Finally, variables of a significant level $(p<0.05)$ were reported with Adjusted Odds Ratio (AOR) with $95 \% \mathrm{Cl}$ as independent determinants of female genital mutilation in Ethiopia.

\section{Results And Discussion}

Among the reproductive age women, $1,266(17.46 \%)$ have said female genital mutilation should be continued and 1,710 (23.6\%) of them believed that FGM is required by their religion. Nearly all women 7,157 (98.66\%) were heard about FGM while 5,232 (72.19\%) of them had no continuous media exposure (Table 1 and 2 ).

Table 1: Weighted proportion of Socio-demographic and economic variables of women in reproductive age in Ethiopia, EDHS 2016 perspective

\begin{tabular}{|c|c|c|c|c|}
\hline \multirow[t]{2}{*}{ uriable name } & \multirow[t]{2}{*}{ Category } & \multicolumn{2}{|c|}{ Female Genital Mutilation } & \multirow[t]{2}{*}{ Total (\%) } \\
\hline & & No & Yes & \\
\hline \multicolumn{5}{|c|}{ re in years of respondents } \\
\hline & $15-30$ & 1535 & 2538 & 4073(56.19) \\
\hline & $>30$ & 612 & 2563 & $3176(43.81)$ \\
\hline \multicolumn{5}{|c|}{ ace of residence } \\
\hline & Urban & 741 & 9924 & 1665(22.97) \\
\hline & Rural & 1406 & 4177 & $5583(77.03)$ \\
\hline \multicolumn{5}{|l|}{ ligion } \\
\hline & Orthodox & 1301 & 1858 & $3157(43.56)$ \\
\hline & Muslim & 346 & 1942 & $2288(31.56)$ \\
\hline & Protestant & 448 & 1226 & 1674(23.09) \\
\hline & Other & 52 & 77 & $129(1.79)$ \\
\hline \multicolumn{5}{|c|}{ urrent occupation } \\
\hline & Currently not working & 1386 & 3378 & $4746(65.47)$ \\
\hline & Currently working & 780 & 1723 & $2503(34.53)$ \\
\hline \multicolumn{5}{|l|}{ arital status } \\
\hline & Never in union & 885 & 942 & 1826(25.19) \\
\hline & Currently in union & 1047 & 3637 & $4711(64.99)$ \\
\hline & Formerly in union & 188 & 523 & $711(9.82)$ \\
\hline \multicolumn{5}{|l|}{ ealth index } \\
\hline & Poor & 620 & 1791 & $2411(33.27)$ \\
\hline & Middle & 322 & 1086 & 1408(19.43) \\
\hline & Rich & 1205 & 2223 & $3429(43.3)$ \\
\hline \multicolumn{5}{|c|}{ ghest educational level of women } \\
\hline & No formal education & 647 & 2757 & $3406(49.99)$ \\
\hline & Primary & 843 & 1662 & $2505(34.56)$ \\
\hline & Secondary & 437 & 452 & $889(12.27)$ \\
\hline & Higher & 221 & 227 & $448(6.19)$ \\
\hline
\end{tabular}

Table 2: Weighted proportion of variable associated with female genital mutilation in Ethiopia among reproductive age women, EDHS 2016 perspective. 


\begin{tabular}{|c|c|c|c|c|c|}
\hline \multirow[t]{2}{*}{ riable name } & \multirow[t]{2}{*}{ Category } & \multicolumn{3}{|c|}{ Female Genital Mutilation(FGM) } & \multirow[t]{2}{*}{ Total (\%) } \\
\hline & & No & & Yes & \\
\hline \multicolumn{6}{|c|}{ iM required by religion } \\
\hline & Yes & 198 & & 1521 & $1710(23.6)$ \\
\hline & No & 1815 & & 3410 & $5226(72.09)$ \\
\hline & Other & 133 & & 179 & $312(4.31)$ \\
\hline \multicolumn{6}{|c|}{ IM to be continued } \\
\hline & Continue & 98 & 1168 & & $1266(17.46)$ \\
\hline & Stop & 1964 & 3784 & & $5748(79.3)$ \\
\hline & Depends on & 88 & 149 & & $234(3.24)$ \\
\hline \multicolumn{6}{|l|}{ edia Exposure } \\
\hline & Non Frequent & 1344 & 3888 & & $5232(72.19)$ \\
\hline & Frequent & 803 & 1213 & & $2016(27.81)$ \\
\hline \multicolumn{6}{|c|}{ rer heard of FGM } \\
\hline & No & 60 & 37 & & $97(1.34)$ \\
\hline & Yes & 2087 & 5064 & & $7151(98.66)$ \\
\hline
\end{tabular}

Considering the prevalence of female genital mutilation Our analysis points out, the prevalence of FGM (65\%) was lower as compared to previous studies conducted in Ethiopia (23), Burkina Faso (24), Sudan(25) but higher than studies conducted in Senegal(26). Female genital mutilation had spatial dependency at the national and regional levels (Moran's I: $0.48, p<0.001$ ). Thus, further analysis is required to detect specific local level significant clusters. We applied Getis-Ord Gi* statistics to detect hot and cold spot clusters.

Figure 1: Global spatial autocorrelations of Female genital mutilation among reproductive age women in Ethiopia. Data from Ethiopian Demographic and Health Survey 2016. The shape file of the map is from https://africaopendata.org/dataset/ethiopiashapefiles.

Female genital mutilation is spatially clustered in Ethiopia (Moran's $\mathrm{I}=0.48, \mathrm{P}<0.001$ ). Accordingly, significant hotspot clusters of FGM were detected in Eastern Amhara, West and North-east Oromia, and East and North-east SNNP regions, Harari, Dire Dawa while cold spot clusters were found in most parts of Tigray, and Gambela, including Central and South-West Afar regions (Figure 2). This finding is supported by other studies conducted in Ethiopia where FGM was spatially clustered with high spot clusters found in Central and East Amhara, North part of SNNP, East Oromia (23). This might be due to different cultural beliefs; in some regions of Ethiopia people believes FGM can reduces sexual hyperactivity, circumcised women are more faithful for their husbands $(14,27)$. Gambela and Tigray regions were cold spots most of the people in this region live in urban areas and being urban residence reduces the chance and support of female genital mutilations(28). Other studies conducted in Kenya(29), Senegal(26),Nigeria(30) all showed that FGM has significant spatial variation (See Figure 2).

Figure 2: Spatial clustering of Female genital mutilation among reproductive age women in Ethiopia. Data from Ethiopian Demographic and Health Survey 2016. The shape file of the map is from https://africaopendata.org/dataset/ethiopia-shapefiles. A single dot represents one enumeration area. Z-score >1.96 implies hotspot, <-1.96 cold spot and others none significant.

Based on the ordinary kriging interpolation, regions like Afar and Somali were estimated to be the high risk regions which were nonsignificant regions by the hot-spot analysis using the Getis-Ord Gi* statistics. This difference might be due to variation in sample size. As we witnessed from the report Amhara and Oromia regions account largest sample sizes while Afar and Somali were the lowest. While most part of Tigray and Gambela regions were low risks as compared to other regions (See Figure 3).

Figure 3: Empirical Bayesian kriging interpolations of Female genital mutilation among reproductive age women in Ethiopia. Data from Ethiopian Demographic and Health Survey 2016. The shape file of the map is from https://africaopendata.org/dataset/ethiopiashapefiles.

\section{Determinant factors of female genital mutilation in Ethiopia}

The fourth Model that includes both the individual and community level variables was the better fit as compared to others with high LLR (Table 3). 
Table 3: Multi-level mixed effect logistic regression analysis output of Female genital mutilation in Ethiopia, EDHS 2016 perspective

\begin{tabular}{|c|c|c|c|c|c|c|c|c|c|}
\hline \multirow[t]{2}{*}{$\begin{array}{l}\text { Variable } \\
\text { name }\end{array}$} & \multirow[t]{2}{*}{ Category } & \multicolumn{3}{|c|}{$\begin{array}{l}\text { Female Genital } \\
\text { Mutilation }\end{array}$} & \multirow{2}{*}{\multicolumn{2}{|c|}{ COR(95\% CI) }} & \multirow[t]{2}{*}{ Model 2} & \multirow[t]{2}{*}{ Model 3} & \multirow[t]{2}{*}{ Model 4} \\
\hline & & No & $\mathrm{Ye}$ & & & & & & \\
\hline \multicolumn{10}{|c|}{ Age of respondent } \\
\hline \multicolumn{2}{|c|}{$\begin{array}{c}\text { Age of respondent } \\
15-30\end{array}$} & 1535 & \multicolumn{2}{|c|}{2538} & \multicolumn{2}{|l|}{1} & \multicolumn{2}{|l|}{1} & \\
\hline \multicolumn{2}{|c|}{$>30$} & 612 & 25 & & $4.62(3.50,6.11)$ & & $2.32(1.71,3.09)$ & & $2.41(1.78,3.26)$ \\
\hline \multicolumn{10}{|c|}{ Current occupation } \\
\hline \multirow{2}{*}{\multicolumn{3}{|c|}{$\begin{array}{l}\text { Currently not working } \\
\text { Currently working }\end{array}$}} & 1386 & 3378 & \multicolumn{2}{|l|}{$0.71(0.54,0.93)$} & \multicolumn{2}{|l|}{$0.75(0.58,0.96)$} & $0.71(0.55,0.92)$ \\
\hline & & & 780 & 1723 & 1 & & 1 & & \\
\hline \multicolumn{10}{|c|}{ Marital status } \\
\hline \multicolumn{3}{|c|}{ Never in union } & 885 & 942 & $0.16(0.12,0.23)$ & & $0.31(0.22,0.42)$ & & $0.31(0.22,0.44)$ \\
\hline & rrently in union & & 1047 & 3637 & 1 & & 1 & & \\
\hline & rmerly in union & & 188 & 523 & $1.06(0.76,1.48)$ & & $0.93(0.65,1.33)$ & & $0.92(0.63,1.32)$ \\
\hline Wealth in & lex & & & & & & & & \\
\hline Po & & 620 & 17 & & $1.23(0.94,1.66)$ & & $0.87(0.62,1.21)$ & & $0.75(0.53,1.08)$ \\
\hline & ddle & 322 & 10 & & $1.35(0.99,1.84)$ & & $1.12(0.78,1.62)$ & & $1.07(0.74,1.55)$ \\
\hline $\mathrm{Ri}$ & & 1205 & 22 & & 1 & & 1 & & 1 \\
\hline FGM to $b$ & continued or s & topped & & & & & & & \\
\hline & ntinue & 98 & & 1168 & $4.87(3.11,7.65)$ & & $\begin{array}{l}4.36(2.73, \\
6.96)\end{array}$ & & $2.86(1.75,4.68)$ \\
\hline St & & 196 & & 3784 & 1 & & 1 & & 1 \\
\hline & pends on & 88 & & 149 & $0.94(0.55,1.63)$ & & $0.61(0.34,1.07$ & & $0.52(0.27,0.98)$ \\
\hline Media Ex & osure & & & & & & & & \\
\hline & n Frequent & & 1344 & 3888 & $1.67(1.27,2.20)$ & & $1.30(0.94,1.81)$ & & $1.30(0.91,1.85)$ \\
\hline & quent & & 803 & 1213 & 1 & & 1 & & 1 \\
\hline Ever hear & d of FGM & & & & & & & & \\
\hline $\mathrm{Nc}$ & & 60 & 37 & & $0.27(0.10,0.72)$ & & $0.25(0.08,0.76)$ & & $0.22(0.08,0.62)$ \\
\hline $\mathrm{Ye}$ & & 2087 & 50 & & 1 & & 1 & & 1 \\
\hline Highest e & ducational level & of wom & & & & & & & \\
\hline & education & 647 & 27 & & $4.93(3.20,7.60)$ & & $1.96(1.21,3.17)$ & & $1.67(1.03,2.71)$ \\
\hline & mary & 843 & 16 & & $1.40(0.98,2.00)$ & & $1.23(0.82,1.85)$ & & $1.10(0.73,1.66)$ \\
\hline & condary & 437 & 45 & & $0.94(0+.66,1.35)$ & & $1.17(0.79,1.74)$ & & $1.12(0.74,1.67)$ \\
\hline & gher & 221 & 22 & & 1 & 1 & & & 1 \\
\hline Place of $r$ & sidence & & & & & & & & \\
\hline & ban & 741 & 99 & & 1 & & & 1 & 1 \\
\hline $\mathrm{Ru}$ & & 1406 & 41 & & $2.79(1.99,3.92)$ & & & $1.89(1.36,2.63)$ & $1.32(0.83,2.09)$ \\
\hline Religion & & & & & & & & & \\
\hline & thodox & 1301 & 18 & & 1 & & & 1 & 1 \\
\hline & sslim & 346 & 19 & & $4.69(3.15,7.000$ & & & $3.70(2.48,5.50)$ & $\begin{array}{l}3.90(2.50, \\
6.09)\end{array}$ \\
\hline & testant & 448 & 12 & & $1.64(1.10,2.45)$ & & & $1.63(1.09,2.46)$ & $1.76(1.05,2.97)$ \\
\hline & & 52 & 77 & & $1.57(0.76,3.24)$ & & & $\begin{array}{l}1.40(0.69 \\
2.87)\end{array}$ & $\begin{array}{l}1.42(0.53 \\
3.77)\end{array}$ \\
\hline FGM requ & ired by religion & & & & & & & & \\
\hline $\mathrm{Ye}$ & & 198 & 15 & & $3.25(2.30,4.77)$ & & & $\begin{array}{l}2.79(1.98 \\
3.94)\end{array}$ & $1.99(1.32,2.99)$ \\
\hline No & & 1815 & 34 & & 1 & & & 1 & 1 \\
\hline & her & 133 & 17 & & $0.99(0.66,1.48)$ & & & $1.03(0.69,1.52)$ & $1.00(0.61,1.65)$ \\
\hline Random c & oefficient & & & & & & & & \\
\hline & Variance & & & & & & $4.58(3.62,5.80)$ & $2.85(2.25,3.59)$ & $3.81(3.00,4.82)$ \\
\hline & ICC & & & & & $0.61(0.56,0.65)$ & $0.57(0.52,0.62)$ & $0.60(0.55,0.64)$ & $0.47(0.42,0.53)$ \\
\hline Model & $\mathrm{AIC}$ & & & & & & 6263 & 6505.916 & 5794.48 \\
\hline comparis & LLR & & & & & & -2947.0897 & -3244.958 & -2876.2411 \\
\hline
\end{tabular}

Model 1: null model; model 2: individual level variables; Model 3: community level variables; Model 4: final model with both individual and community level variables; AIC: Akakie Information Criteria; BIC: Bayessian Information Criteria; LLR: Log Likelihood Ratio

Women older than 30 years had more than double (AOR=2.41, 95\% Cl: 1.78, 3.26) odds of having FGM compared to women of age $\leq 30$ years. This finding was supported by different studies conducted in Ethiopia $(23,31)$, and Ghana (32). This might be due to the strong emphasis is given by the government of Ethiopia in the late $20^{\text {th }}$ and early $21^{\text {st }}$ century to eliminate the practice of FGM through empowering women in different strategies including providing access to mass media and education. This would mean that women 
who were older have missed access to media exposure, health education, and other opportunities by health extension workers that can condemn female genital mutilation.

With regard to occupation, women who are not currently working had $29 \%(\mathrm{AOR}=0.71,95 \% \mathrm{Cl}: 0.55,0.92)$ less odds of having FGM as compared to their counterpart. A number of studies, however, have reported that women who have occupation/are working had lesser odds of practicing FGM than those who have no occupation $(27,33,34)$. To best of our knowledge, there is no clear justification for this finding.

Those mothers who are never in the union had $69 \%$ (AOR=0.31,95\% Cl: $0.22,0.44)$ reduced odds of having FGM compared to women who are currently in Union. This finding is in agreement with studies conducted in Sudan where not currently married women had less odds of having FGM (25). In Somali and Harari regional states of Ethiopia the communities circumcise the women to increase marriageability, to make them calm and sexually faithful for their husbands(27). The reason for being never in union reduces the odds of having FGM in Ethiopia might be the different cultural barriers like being circumcised makes females more faithful to their husbands (35). In African countries including Ethiopia, some communities believe that practicing FGM as a pre-request for marriage $(19,36,37)$. Additionally, if women do not practice FGM, they might be excluded from the community (36).

Those women whose intention about FGM to be continued had nearly $3(\mathrm{AOR}=2.86,95 \% \mathrm{Cl}: 1.75,4.68)$ times more odds of having FGM compared to those who think FGM to be stopped while those who think of FGM to be continued conditionally had $48 \%$ ( $A O R=0.52,95 \% \mathrm{Cl}: 0.27,0.98$ ) less odds of having FGM compared to those whose intention is FGM to be stopped. This might be due to mothers who support that FGM should be continued are old aged, and uneducated. Even if FGM is declared as an illegal act, male attitude (37), lack of female autonomy and older people's beliefs of FGM as a source to keep virginity make some older people have intentions as FGM to be a continued arena (32). Those mothers living in a community where FGM is required by religion had 2 $(A O R=1.99,95 \% \mathrm{Cl}: 1.32,2.99)$ times the odds of having FGM as compared to women where FGM is not required by religion. Uncircumcised women were considered as breaching the Muslim religion and they believe as one prerequisite for being a Muslim religion follower (35). "In the Muslim religion, we believe that if we are not circumcised, we feel that we are totally against our religion. Allah will never accept us whatever we pray. This is the reason we allow our daughters to practice FGM"(27).

In contrast to findings from other studies, mothers who had ever heard about FGM had nearly $3 / 4^{\text {th }}(\mathrm{AOR}=0.22,95 \% \mathrm{Cl}: 0.08,0.62)$ reduced odds of having FGM compared to their counterparts. This finding is against in studies conducted in Sudan where having more formal education reduces the odds of having FGM (25), Ghana (32). Many scholars have documented that religion and different traditional and cultural factors could affect the practice of FGM. Accordingly, our study noted that Muslim and protestant religious followers had nearly four [AOR=3.90,95\% Cl: $2.5,6.09)$ and nearly two times (AOR=1.76, 95\%Cl: $1.05,2.97)$ increased odds of being circumcised as compared to orthodox religion followers. This finding is supported by studies conducted in South Ethiopia(31), the Somali region of Eastern Ethiopia(33), Ethiopia(23). In addition, those mothers living in a community where FGM is required by religion had 2 (AOR=1.99, 95\% Cl: 1.32, 2.99) times the odds of having FGM as compared to women where FGM is not required by religion. This finding was supported by different studies conducted elsewhere in South Ethiopia (31), Ethiopia (23). The main reason for the increased practice of FGM in such a religious community is related to the strong belief and attitude of the community that practicing FGM has a religious basis. For instance, a girl who undergo circumcision is considered to be pure and can go for pray and it is considered as an obligation in Islamic religion (35).

In the context of women education, women who had no education had more than one and a half $(\mathrm{AOR}=1.67,95 \% \mathrm{Cl}: 1.03,2.71)$ odds of having FGM as compared to those who had above secondary education. Similar results have been reported by different studies in South Ethiopia (31), and Ghana(32). It is evidenced that more educated women can save their daughters form circumcision (38). Mostly, women circumcised their children to get social acceptance and marriage prospects which might be related to the women's selfautonomy that would mean more educated women had better decision-making ability (39).

\section{Conclusions}

Female genital mutilation was spatially clustered. And hotspot clusters were found in Amhara, Oromia and SNNPR regions. Age of the mother, religion, occupation, educational level, marital status, information about female genital mutilation, and intention about FGM to be stopped or continued were significantly associated to Female genital mutilation. It is recommended to give more emphasis on hot spot regions and consider the above-listed variables to reduce the magnitude of female genital mutilation in Ethiopia. Researchers are 
also recommended to consider the qualitative aspects related with cultural, social and religious perspectives related to FGM as these variables were not well addressed by our study

\section{List Of Abbreviations}

FGM: Female Genital Mutilation, AOR: Adjusted Odds Ratio, EDHS: Ethiopian Demographic and Health Survey, EA: Enumeration Area, LLR: Log Likelihood Ratio, RR: Relative Risk

\section{Declarations}

\section{Ethics approval and consent to participate}

Permission for data access was obtained from Major DHS program after registered as authorized user. All the data used for this manuscript are publically available and confidentiality was maintained anonymously.

\section{Consent for publication}

Not applicable

\section{Availability of data and material}

The data used for preparation of this manuscript are available from http://www.dhsprogram.comand anyone can access through online request as authorized user. The authors prepared the data that was used for preparation of this manuscript can be shared if required. The shape files of the maps were freely available without any restriction at Open Africa (https://africaopendata.org/dataset/ethiopia-sha.pefiles).

\section{Competing interests}

The authors declare that they have no competing interests.

\section{Funding}

No funding organization

\section{Authors' contributions}

AG, GM and MW developed the proposal, extracted the data, worked on analysis, interpreted the results and prepared the manuscript. All authors were contributing equally for the development of this research work.

\section{Acknowledgements}

The authors are happy to acknowledge the Institute of Public Health, College of Medicine and Health Science, University of Gondar. Our thanks also extend to the international Major DHS program for giving permission for data access.

\section{References}

1. World Health Organization. WHO guidelines on the management of health complications from female genital mutilation. World Health Organization; 2016.

2. WHO. WHO guidelines on the management of health complications from female genital mutilation. Swezerland, Geneva,: WHO; 2016.

3. UNICEF. Female genital mutilation/cutting 2016 [Available from: https://www.unicef.org/media/files/FGMC_2016_brochure_final_UNICEF_SPREAD.pdf.

4. WHO. Female genital mutilation and other harmful practices. 2016.

5. WOrld Health Organization. Female genital mutilation (FGM). 2016. 
6. Central Statistical Agency (CSA) [Ethiopia] and ICF. Ethiopia Demographic and Health Survey 2016. Addis Ababa, Ethiopia, and Rockville,Maryland, USA,: CSA and ICF; 2016.

7. Kandala N, Komba P, O U. Secular trends in the prevalence of Female Genital Mutilation/Cuttings among girls: a systematic analysis. BMJ Global Health, 2017.

8. Berg RC, Denison E. A tradition in transition: factors perpetuating and hindering the continuance of female genital mutilation/cutting (FGM/C) summarized in a systematic review. Health care for women international. 2013;34(10):837-59.

9. Andro A, Cambois E, Lesclingand M. Long-term consequences of female genital mutilation in a European context: Self perceived health of FGM women compared to non-FGM women. Social science \& medicine. 2014;106:177-84.

10. Bjälkander O, Bangura L, Leigh B, Berggren V, Bergström S, Almroth L. Health complications of female genital mutilation in Sierra Leone. International journal of women's health. 2012;4:321.

11. Brady M. Female genital mutilation: complications and risk of HIV transmission. AIDS patient care and STDs. 1999;13(12):709-16.

12. Toubia N. Female circumcision as a public health issue. New England Journal of Medicine. 1994;331(11):712-6.

13. Wuest S, Raio L, Wyssmueller D, Mueller M, Stadlmayr W, Surbek D, et al. Effects of female genital mutilation on birth outcomes in Switzerland. BJOG: An International Journal of Obstetrics \& Gynaecology. 2009;116(9):1204-9.

14. Yirga WS, Kassa NA, Gebremichael MW, Aro AR. Female genital mutilation: prevalence, perceptions and effect on women's health in Kersa district of Ethiopia. International journal of women's health. 2012;4:45.

15. Mulongo P, Hollins Martin C, McAndrew S. The psychological impact of female genital mutilation/cutting (FGM/C) on girls/women's mental health: a narrative literature review. Journal of Reproductive and Infant Psychology. 2014;32(5):469-85.

16. Berg RC, Denison EM-L, Fretheim A. Psychological, social and sexual consequences of female genital mutilation/cutting (FGM/C): a systematic review of quantitative studies: Norwegian Knowledge Centre for the Health Services; 2010.

17. Egbuonu Al, Ifeoma. The prevalence and practice of female genital mutilation in Nnewi, Nigeria: the impact of female education. Journal of Obstetrics and Gynaecology. 2000;20(5):520-2.

18. Ibrahim BS, Ahmed ZD, Ado AYu, Mohammed Y, Abubakar AA, Balogun MS, et al. Prevalence and Determinants of Female Genital Mutilation among Women in a Rural Settlement of Kano State Nigeria, 2016. 2017.

19. Shiferaw D, Deyessa N, Fufa G, Kinati T, Desalegn M. Prevalence and associated factors of female genital mutilation among high school students in Dale Wabera Woreda, Oromia Regional State, Ethiopia. International Journal of Medicine and Medical Sciences. 2017;9(6):72-8.

20. World Health Organization. World health statistics 2016: monitoring health for the SDGs sustainable development goals: World Health Organization; 2016.

21. Nour NM. Female genital cutting: impact on women's health. Seminars in reproductive medicine. 2015;33(1):41-6.

22. Hosmer Jr DW, Lemeshow S, Sturdivant RX. Applied logistic regression: John Wiley \& Sons; 2013.

23. Setegn T, Lakew Y, Deribe K. Geographic Variation and Factors Associated with Female Genital Mutilation among Reproductive Age Women in Ethiopia: A National Population Based Survey. PLoS One. 2016;11(1):e0145329.

24. Chikhungu LC, Madise NJ. Trends and protective factors of female genital mutilation in Burkina Faso: 1999 to 2010. International journal for equity in health. 2015;14:42.

25. Elduma AH. Female genital mutilation in Sudan. Open access Macedonian journal of medical sciences. 2018;6(2):430.

26. Kandala NB, Komba PN. Geographic variation of female genital mutilation and legal enforcement in sub-Saharan Africa: a case study of Senegal. The American journal of tropical medicine and hygiene. 2015;92(4):838-47.

27. Abathun AD, Sundby J, Gele AA. Attitude toward female genital mutilation among Somali and Harari people, Eastern Ethiopia. International journal of women's health. 2016;8:557.

28. Mariam AG, Hailemariam A, Belachew T, Michael KW, Lindstrom D. Support for the continuation of female genital mutilation among adolescents in Jimma zone, Southwest Ethiopia. Ethiopian journal of health sciences. 2009;19(2).

29. Achia TN. Spatial modelling and mapping of female genital mutilation in Kenya. BMC public health. 2014;14(1):276.

30. Kandala N-B, Nwakeze N, Kandala SNI. Spatial distribution of female genital mutilation in Nigeria. The American journal of tropical medicine and hygiene. 2009;81(5):784-92.

31. Gebremariam K, Assefa D, Weldegebreal F. Prevalence and associated factors of female genital cutting among young adult females in Jigjiga district, eastern Ethiopia: a cross-sectional mixed study. International journal of women's health. 2016;8:357.

Page 9/12 
32. Sakeah E, Debpuur C, Oduro AR, Welaga P, Aborigo R, Sakeah JK, et al. Prevalence and factors associated with female genital mutilation among women of reproductive age in the Bawku municipality and Pusiga District of northern Ghana. BMC women's health. 2018;18(1):150.

33. Mohamud M, Kaba M, Tamire MM. Assessment of barriers of behavioral change to stop FGM practice among women of Kebri Beyah district, Somali regional state, eastern Ethiopia. Global Journal of Medical Research. 2017.

34. Ashimi AO, Amole TG, Iliyasu Z. Prevalence and predictors of female genital mutilation among infants in a semi urban community in northern Nigeria. Sexual \& Reproductive Healthcare. 2015;6(4):243-8.

35. Bogale D, Markos D, Kaso M. Intention toward the continuation of female genital mutilation in Bale Zone, Ethiopia. International journal of women's health. 2015;7:85.

36. Insight I. The dynamics of social change towards the abandonment of female genital mutilation/cutting in five African countries. UNICEF; 2010.

37. Shahid U, Rane A. African, male attitudes on female genital mutilation: an Australian survey. Journal of obstetrics and gynaecology : the journal of the Institute of Obstetrics and Gynaecology. 2017;37(8):1053-8.

38. Ashimi AO, Amole TG, Iliyasu Z. Prevalence and predictors of female genital mutilation among infants in a semi urban community in northern Nigeria. Sexual \& reproductive healthcare : official journal of the Swedish Association of Midwives. 2015;6(4):243-8.

39. Oljira T, Assefa N, Dessie Y. Female genital mutilation among mothers and daughters in Harar, eastern Ethiopia. International journal of gynaecology and obstetrics: the official organ of the International Federation of Gynaecology and Obstetrics. 2016;135(3):304-9.

\section{Figures}
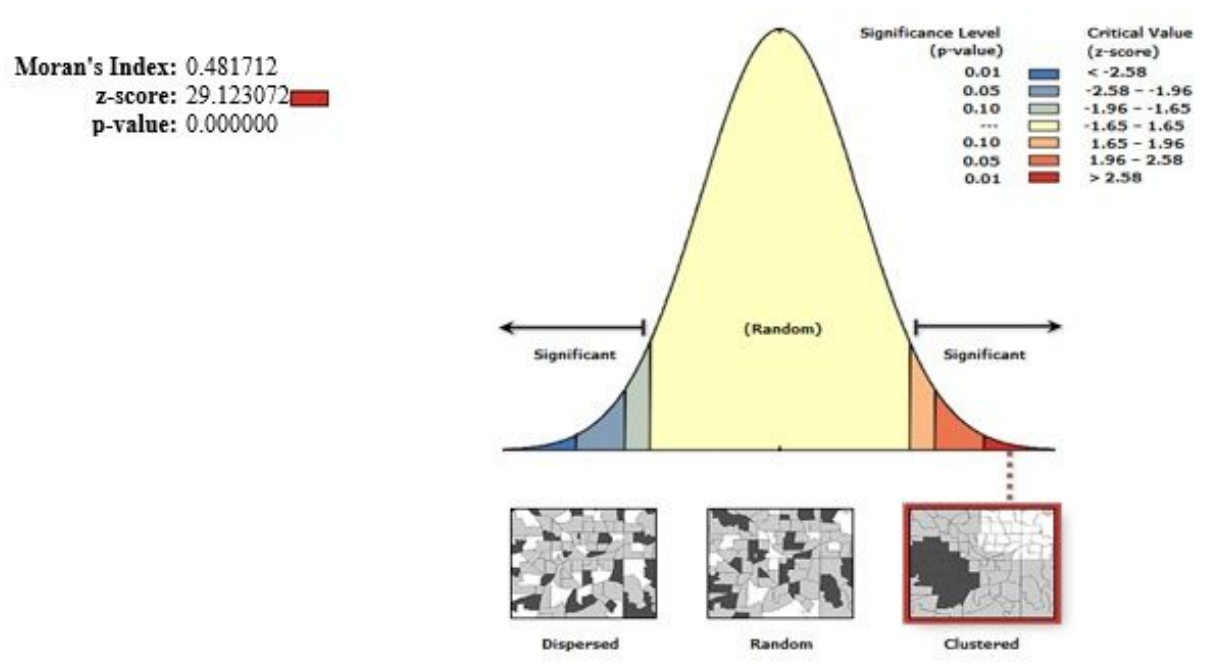

\section{Figure 1}

Global spatial autocorrelations of Female genital mutilation among reproductive age women in Ethiopia. Data from Ethiopian Demographic and Health Survey 2016. The shape file of the map is from https://africaopendata.org/dataset/ethiopia-shapefiles. 


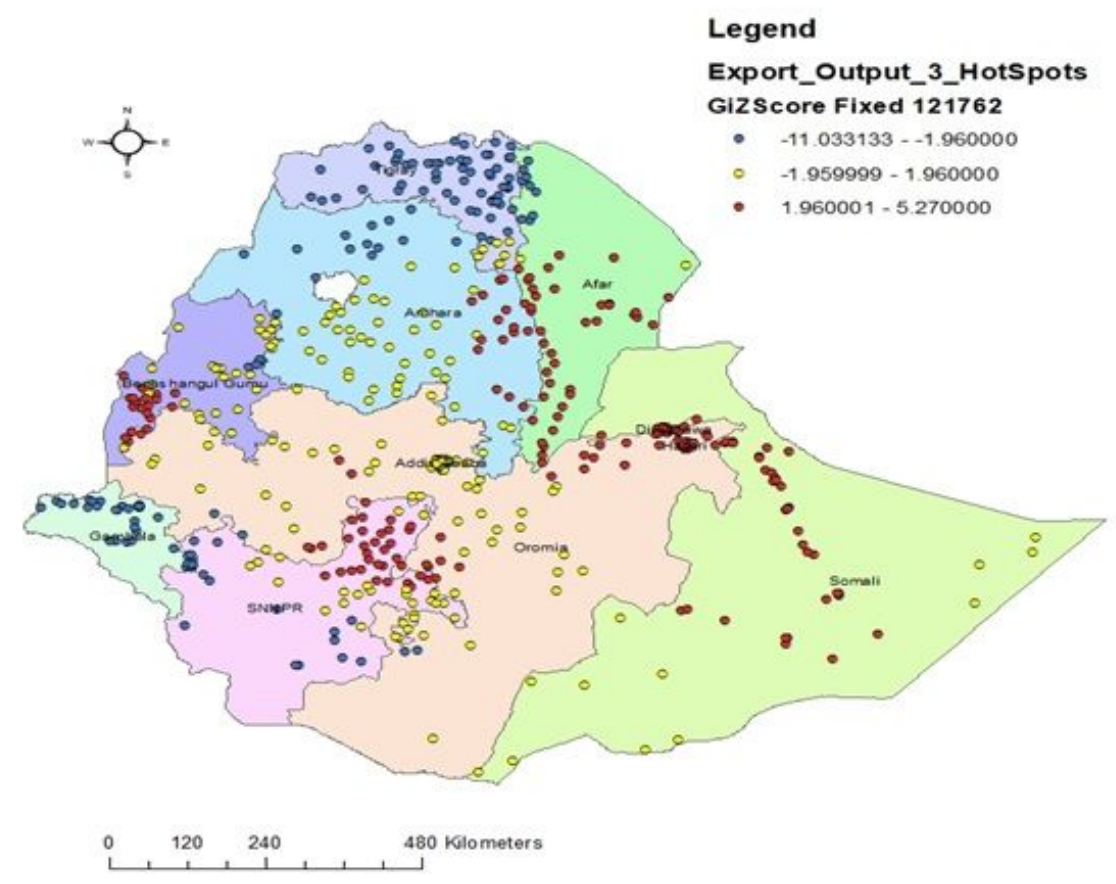

Hotspots of FGM in Ethiopia

Figure 2

Spatial clustering of Female genital mutilation among reproductive age women in Ethiopia. Data from Ethiopian Demographic and Health Survey 2016. The shape file of the map is from https://africaopendata.org/dataset/ethiopia-shapefiles. A single dot represents one enumeration area. Z-score $>1.96$ implies hotspot, $<-1.96$ cold spot and others none significant. 


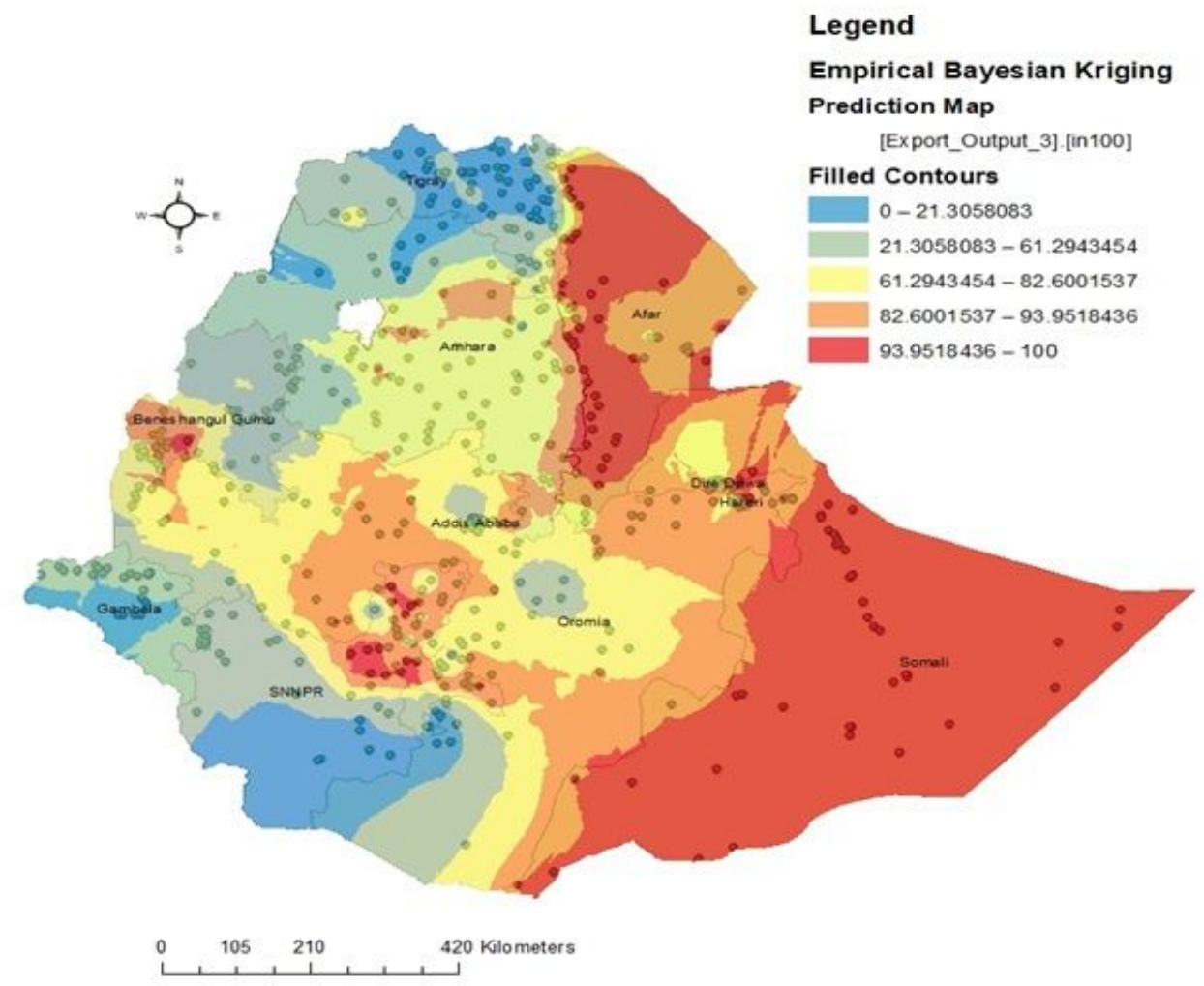

Empirical Bayesian Kriging prediction map

\section{Figure 3}

Empirical Bayesian kriging interpolations of Female genital mutilation among reproductive age women in Ethiopia. Data from Ethiopian Demographic and Health Survey 2016. The shape file of the map is from https://africaopendata.org/dataset/ethiopiashapefiles. 